\title{
A experiência de incubar um empreendimento solidário formado por usuários de saúde mental
}

\author{
The experience of a solidarity incubation project formed by mental health users
Priscila Tagliaferro Rojo ${ }^{1}$, Carmen Lúcia Alves Filizola², Sônia Regina Zerbetto ${ }^{3}$, Ana Lúcia Cortegoso ${ }^{4}$

\begin{abstract}
RESUMO
Introdução: Da articulação dos atores da saúde mental e da economia solidária de um município paulista foi criado um grupo solidário, em processo de incubação por meio de parceria entre o Centro de Atenção Psicossocial e uma Incubadora de Cooperativas Populares. A incubação é um processo de assessoria a grupos para formação e consolidação de empreendimentos econômicos. O método de incubação dessa incubadora compreende dezesseis classes de comportamentos.

Objetivo: Descrever e refletir sobre a experiência de incubação desse grupo.

Materiais e Métodos: Nesta pesquisa qualitativa, foram utilizadas várias fontes de dados, tais como relatórios, projetos, atas de reunião, entre outros. Todos os cuidados éticos foram observados.

Resultados: A partir da análise dos documentos, encontrou-se que é relevante a construção de parcerias e o envolvimento da comunidade no processo de inclusão social pelo trabalho de usuários de saúde mental. Enfatiza-se a importância da presença dos técnicos no grupo, entendendo-a como tutela de direito à saúde. Considera-se que há ainda os desafios de concretizar a autogestão e operacionalizar a transformação dos usuários em trabalhadores/sócios. Conclusão: Espera-se com esta pesquisa contribuir para a reflexão de outras experiências e também para o conhecimento sobre metodologia de incubação na saúde mental.
\end{abstract}

Palavras-chave: reabilitação; economia; metodologia; tecnologia.

\section{ABSTRACT}

Introduction: From the articulation of mental health and social economy actors in a city of São Paulo, a solidarity group was created trough an incubation process using the partnership between the Center for Psychosocial Care and the Regional Incubator for Popular Cooperatives. The incubation is an advisory process for groups in the formation and consolidation of economic enterprises. The incubation method of this incubator comprises sixteen classes of behavior.

Objective: To describe and reflect on the process of incubation performed by this group.

Materials and Methods: In this qualitative research, we used multiple data sources, such as reports, projects, meeting minutes, among others. All ethical guidelines were followed.

Results: From the analysis of the documents, it was found that is relevant the building of partnerships and the community involvement in the process of social inclusion by the work of mental health users. We emphasize the importance of the technicians' presence in the group, understanding it as the right to health protection. It should be considered that there are still challenges to achieve self-management and operational users in the transformation of workers/members.

Conclusions: It is expected that this research contribute to the reflection of other experiences and also to the knowledge on incubation methodology in mental health.

Keywords: rehabilitation; economics; methodology; technology.

\footnotetext{
"Artigo extraído da Dissertação intitulada "Enfrentando desafios e construindo possibilidades - a experiência da equipe no processo de incubação de um empreendimento solidário formado por usuários de um CAPS", apresentada ao Programa de Pós-graduação do Departamento de Enfermagem da Universidade Federal de São Carlos (UFSCar), 2011. Pesquisa financiada pela Coordenação de Aperfeiçoamento de Pessoal de Nível Superior.

${ }^{1}$ Enfermeira. Mestre em Enfermagem pela UFSCar. Departamento de Enfermagem, UFSCar, São Carlos, Brasil.

${ }^{2}$ Enfermeira. Doutora em Enfermagem pela Escola de Enfermagem da USP-RP. Professora Associada do Departamento de Enfermagem da UFSCar, São Carlos, Brasil.

${ }^{3}$ Enfermeira. Doutora em Enfermagem Psiquiátrica pela Escola de Enfermagem da USP-RP. Professora Adjunta I do Departamento de Enfermagem da UFSCar, São Carlos, Brasil.

${ }^{4}$ Psicóloga. Doutora em Psicologia da Educação pela Pontifícia Universidade Católica de São Paulo. Professora Associada do Departamento de Psicologia da UFSCar, São Carlos, Brasil.
} 


\section{INTRODUÇÃO}

A Reforma Psiquiátrica traz como um de seus principais desafios o processo de inclusão social e promoção da cidadania das pessoas com transtornos mentais, tendo como instrumento potencializador, o trabalho. Em 2004, atores dos campos da Reforma Psiquiátrica e Economia Solidária articularam-se com a finalidade de promover a reinserção social pelo trabalho de usuários de saúde mental por meio da construção de empreendimentos solidários e autogestionários ${ }^{1}$.

Em 2005 foi criado um Grupo de Trabalho Interministerial de Saúde Mental e Economia Solidária (GT), entre os Ministérios da Saúde e do Trabalho e Emprego, com o objetivo de construir e implementar uma política nesta área ${ }^{1}$. Esse grupo, composto por usuários, gestores, profissionais e movimentos sociais, apresentou, em 2006, em seu relatório final, atividades e propostas, definindo quatro eixos norteadores: 1) Mapeamento, Articulação, Redes de Comercialização e Produção; 2) Formação, Capacitação, Assessoria e Incubagem; 3) Financiamento e 4) Legislação. O grupo ainda elaborou um conjunto de propostas para cada um desses eixos ${ }^{2}$.

No eixo dois, o GT apontou a necessidade de criação de metodologias de incubagem dos empreendimentos da saúde mental, junto às Incubadoras Tecnológicas de Cooperativas Populares (ITCPs), utilizando recursos do Programa Nacional de Incubadoras de Cooperativas Populares (PRONINC) e a inclusão do Ministério da Saúde nesse programa com o objetivo de apoiar os processos de incubagem neste campo ${ }^{2}$.

As entidades de apoio e fomento à Economia Solidária são organizações que desenvolvem capacitação, assessoria, incubação, assistência técnica e organizativa e acompanhamento de empreendimentos de trabalho associado ${ }^{3}$. Dentre elas encontram-se as universidades por meio das ITCPs que são iniciativas surgidas em meados da década de 90 , para organizar e qualificar os desempregados históricos a fim de possibilitar a entrada desses excluídos no mercado formal de trabalho por meio da construção de cooperativas ou de empresas autogeridas ${ }^{4,5}$.

A incubação representa um processo de assessoria a grupos para formação e consolidação de empreendimentos solidários. As ITCPs desenvolvem métodos de incubação que abrangem ações educativas, jurídicas e técnico-científicas, que geram instrumentos pedagógicos para gestão e controle das cooperativas ou empreendimentos solidários ${ }^{6}$.

Constata-se que a maioria das incubadoras adota métodos de trabalho que dividem o processo em fases, tais como pré-incubação, incubação e desincubação. Entretanto, há um método constituído por 16 classes de comportamentos assim apresentados: 1) Processar demandas de diferentes atores sociais para incubação de empreendimentos solidários; 2) Identificar população em potencial para formação de empreendimentos solidários; 3) Caracterizar cada um dos atores envolvidos no processo de incubação (grupo em potencial e parceiros); 4) Apresentar a Economia Solidária, como possibilidade de organização coletiva para geração de trabalho e renda, e os projetos da incubadora, sua proposta de trabalho e as condições necessárias para a incubação; 5) Apoiar o grupo em sua organização inicial para que possa tomar decisões democraticamente; 6) Assessorar a organização inicial do grupo para decidir a formação ou não do empreendimento; 7) Elaborar proposta de trabalho em conjunto com o grupo a ser incubado; 8) Promover formação contínua e permanente dos membros do grupo para o cooperativismo e autogestão; 10) Assessorar o grupo na escolha da atividade econômica a partir de estudos de viabilidade e da cadeia produtiva; 11) Promover condições para capacitação técnica do grupo; 12) Assessorar o grupo para implantação do empreendimento com inserção inicial no mercado; 13) Promover elaboração de estatuto e regimento interno de forma participativa e coletiva; 14) Assessorar o grupo para a legalização do empreendimento e implantação de um sistema contínuo e permanente de monitoramento por meio de indicadores; 15) Assessorar o grupo para implementação do empreendimento de forma esporádica; 16) Assessorar o grupo para participação em redes de cooperação e de movimento de Economia Solidária $^{7,8}$.

Diante do exposto, esta pesquisa teve por objetivo descrever e refletir sobre o processo de incubação de um empreendimento solidário formado por usuários de 
um Centro de Atenção Psicossocial (CAPS) de um município do interior paulista fundamentado no método de incubação. Tal estudo se justifica tendo em vista a relevância da produção de uma prática que possibilite a reflexão sobre o referencial técnico-conceitualinstrumental desse novo dispositivo de inclusão social pelo trabalho de usuários de saúde mental, os empreendimentos solidários. Espera-se contribuir para o conhecimento sobre o método de incubação na saúde mental tendo em vista a escassez de estudos dessa temática.

\section{MATERIAIS E MÉTODOS}

Local - o contexto do estudo - a constituição da equipe de incubação

Esta pesquisa descritiva e qualitativa foi realizada com um grupo solidário, por meio da inserção da pesquisadora no contexto do grupo, formado por usuários de saúde mental, em processo de incubação com a parceria do CAPS de um município do interior paulista e de uma incubadora. O grupo foi criado em 2006 e inserido no Cadastro de Iniciativas de Inclusão Social pelo Trabalho (CIST) do Ministério da Saúde em março de 2007. É um grupo informal e tem como atividade produtiva a reciclagem de papel e produção de produtos dele derivados.

A sua incubação foi sendo concretizada por uma equipe constituída por trabalhadores do referido serviço e integrantes da universidade. Dentre os componentes do CAPS, integravam a equipe, durante o período da coleta de dados (março a dezembro de 2009): duas técnicas de nível superior, a coordenadora do serviço, com formação em Terapia Ocupacional, que se encontrava no processo desde o início em 2005, uma psicóloga que integrou o grupo em meados de 2006 e, ainda, quatro técnicas de nível médio, auxiliares de enfermagem que, em sua maioria (três), apoiavam o grupo desde o início.

Dos integrantes da universidade, a equipe sempre contou com uma professora do Departamento de Enfermagem, Coordenadora Docente de Projeto de Incubação integrante da incubadora que participava do processo desde o início; uma técnica de nível superior que exercia a função de Coordenadora Executiva de
Projeto de Incubação da Incubadora Regional de Cooperativas Populares (INCOOP) com carga horária semanal de 20 horas. O grupo teve duas delas: uma que o assessorou no período de fevereiro a dezembro de 2007 (com formação em sociologia) e a presente no período de coleta de dados, com formação na área de saúde mental (psicologia), considerando a decisão dos coordenadores do processo que, para a incubação de empreendimento na área, fazia-se necessário que esse técnico tivesse formação em saúde mental. Essa trabalhadora passou a integrar a equipe no final de 2008 , tendo em vista que a contratação desse técnico é viabilizada mediante contrato temporário com recursos oriundos do PRONINC.

Dentre os alunos, o grupo sempre contou com dois bolsistas de extensão com carga horária de oito horas semanais, pois, na universidade, o processo se constitui como Projeto de Extensão recebendo, portanto, recursos oriundos da Pró-Reitoria de Extensão. Além desses, sempre contou com alunos de graduação de vários cursos que realizavam atividades ligadas a: Estágios Curriculares (Enfermagem e Terapia Ocupacional), Monografias ou Trabalhos de Conclusão de Curso e de Projeto de Bolsa Treinamento (ligado a recursos oriundos da Pró-Reitoria de Graduação da universidade). Também participavam alunos que realizavam atividades de intervenção da disciplina Atividade Curricular de Integração Ensino, Pesquisa e Extensão (ACIEPE) denominada "Cooperativas Populares e Economia Solidária" ofertada por integrantes da INCOOP. No período de 2008 a 2010, contou com duas alunas de pós-graduação em enfermagem que, como parte da pesquisa, também integravam a equipe.

\section{Coleta e análise dos dados}

Utilizou-se de consulta a documentos produzidos no processo de incubação, tais como projetos, relatórios de extensão, documentos do empreendimento (atas de reuniões de equipe e de assembleia) e pesquisas divulgadas, representados por meio de codificação na tabela 1. Além disso, uma das pesquisadoras se inseriu na equipe e participou em vários momentos de atividades do trabalho, como: reuniões de equipe e 
TABELA 1 - Codificação dos documentos analisados

\begin{tabular}{lc}
\hline Tipo de documento & Codificação \\
\hline $\begin{array}{l}\text { Documentos do empreendimento (Livro } \\
\text { Ata de Reunião de Equipe/Assembleia) }\end{array}$ & A \\
Relatório de Atividade de Extensão & B \\
Pesquisa & $\mathrm{C}$ \\
Ebook & D \\
Projeto/Proposta de Atividade de & E \\
Extensão & \\
Trabalho de Conclusão de Curso & F \\
\hline
\end{tabular}

apoio ao grupo. Ainda realizou entrevista com a Coordenadora Docente de Projeto de Incubação do grupo.

A análise dos documentos foi feita a partir de uma identificação para cada um deles, constando o tipo de documento, a data, o assunto e um resumo para que se fosse possível conhecer o material coletado e ter acesso a ele de forma sucinta ${ }^{9}$. Após foi feita uma relação da documentação em que a análise se processou por meio de recortes na totalidade construída por cada documento ${ }^{9}$.

Foi realizada ainda a relação dos documentos e a comparação das informações contidas com as necessárias para atender a descrição das dezesseis classes de comportamentos que compõem o método de incubação. Tendo em vista que nem todos os dados se encontravam nos documentos disponíveis, foi preciso buscar tais informações por meio de uma entrevista semiestruturada com a Coordenadora Docente, composta por questões relacionadas ao início do processo de construção do empreendimento, a definição da atividade produtiva e local de produção.

Para análise dos dados utilizou-se do referencial teórico de metodologia de incubação de empreendimentos solidários da INCOOP, pautando-se nas dezesseis classes de comportamentos já abordadas anteriormente.

\section{Procedimentos Éticos}

O projeto foi encaminhado ao Comitê de Ética da UFSCar para análise e aprovado pelo parecer $\mathrm{n}$. $165 / 2009$.

\section{RESULTADOS E DISCUSSÃO}

Com base na experiência de integrar a equipe de incubação, na análise das várias fontes de dados e frente ao referencial teórico do processo de incubação de empreendimentos solidários pautado nas dezesseis classes de comportamento, buscou-se descrever o processo de incubação do empreendimento solidário em estudo e refletir sobre ele. Sua apresentação foi estruturada em dois momentos: o processo de criação do grupo e a assessoria da equipe na consolidação do empreendimento.

O processo de criação do grupo - da apresentação da demanda ao seu processamento - construindo uma realidade

Diante da necessidade de enfrentar o desafio de inclusão social dos usuários do CAPS pelo trabalho e seguindo as diretrizes do Ministério da Saúde, atores do campo da saúde mental do município apresentaram aos coordenadores da incubadora, no segundo semestre de 2005, a demanda de criação de um grupo de produção a ser formado por usuários de saúde mental ${ }^{10}$.

Segundo informações da Coordenadora Docente, a incubadora dessa universidade assessorava empreendimentos solidários em várias cadeias produtivas com pessoas desempregadas, tendo como foco de suas ações os excluídos do mercado. Porém nunca havia incubado empreendimentos constituídos por pessoas com transtornos mentais. Tal fato representou, naquele momento, uma experiência nova para a incubadora, tornando-se 0 primeiro empreendimento de saúde mental a ser incubado por ela.

Para dar andamento ao processo foram realizadas várias reuniões entre os atores, no decorrer das quais, um dos coordenadores da incubadora propôs, como estratégia, a sensibilização da equipe do CAPS sobre os princípios da Economia Solidária e o processo de incubação, tendo em vista ser esta uma das classes de comportamento presentes no método de incubação. Durante essa etapa e, ainda, cumprindo os passos do método, também foram analisados e definidos a atividade produtiva e o processo de inclusão dos usuários no empreendimento. 
Quanto à definição da atividade produtiva, produção de papel reciclado e produtos derivados, anteriormente à sua formalização com a população alvo, essa atividade havia sido analisada pela equipe da incubadora em uma de suas reuniões gerais $(A)$, realizadas semanalmente, no segundo semestre de 2005. Como justificativa dessa escolha a Docente esclareceu a presença de diversas variáveis facilitadoras, tais como: existência de equipamentos, inexistência de grupo de produção de papel artesanal no município, características do próprio contexto como a presença de duas universidades vislumbrando a comercialização de produtos (cadernos, pastas, crachás etc) entre outros. Ainda foi considerado que a utilização da técnica de reciclagem propiciaria baixos custos econômicos para o processo produtivo, tornando-se mais um fator facilitador para criação e sustentabilidade econômica do grupo, além de estar em consonância com um dos princípios da Economia Solidária, ou seja, o respeito à natureza.

A apresentação, discussão e definição da atividade produtiva com a população alvo foram realizadas em diversos momentos tendo sido rediscutidas e formalizadas em uma assembleia no CAPS realizada para esse fim, após sua ampla divulgação, no início de agosto de 2006. Essa assembleia também se constituiu no processo de incubação do grupo, como o passo inicial para a inclusão dos usuários no grupo. Nesse processo, os documentos analisados (A, B) apontaram um número variável de 31 a 35 usuários que aderiram de forma livre, voluntária e esclarecida à ideia de produzir e comercializar papel e produtos derivados seguindo os princípios da Economia Solidária. Assim, ressalta-se que todo o processo teve como princípio a autonomia como meta e não como critério de inclusão ou exclusão, já que os primeiros integrantes não foram selecionados nem indicados pela equipe segundo maior ou menor habilidade. Constata-se que o critério utilizado foi o desejo de participar e a decisão esclarecida de cada um deles.

Entretanto, observa-se nos documentos analisados $(A, C)$ que o grupo, desde o início do processo, contou com um número variável de integrantes, uma vez que ocorreram desistências e entrada de novos sócios.
Sobre essa questão, ressalta-se que, até o final de 2008, a decisão de inserção de novos integrantes no grupo era feita por indicação dos trabalhadores do CAPS $^{11}$. No entanto, após longa discussão na equipe e segundo os princípios da Economia Solidária, foi definido, no início de 2009, que a tomada de decisão sobre a inclusão de novos sócios deveria ser feita pelos "usuários trabalhadores", nas assembleias. Por meio da vivência junto ao grupo pode-se afirmar que essa resolução vem sendo cumprida. Ressalta-se além de sua relevância para o cumprimento do princípio da autogestão, o desafio de concretizá-la na prática da construção cotidiana de um empreendimento solidário.

Quanto ao local de produção, muito embora várias reuniões com a coordenação dos Centros Comunitários e visita a um deles tivessem sido realizadas pela Coordenadora do CAPS e Coordenadora Docente no início de 2006, não foi possível concretizá-lo tendo em vista a necessidade de pequenas adequações físicas. Assim, foi realizada uma reunião com a representante da Secretaria de Cidadania que afirmou a inviabilidade do processo justificando não ser possível atender essa demanda por haver muitas outras prioridades no município. A secretária manifestou-se de forma desfavorável à iniciativa, relatando não acreditar na possibilidade de a atividade se sustentar e por entender que havia risco de conflito com a população da região, pelo fato de o empreendimento ser formado por pessoas com transtorno mental severo ${ }^{12}$.

Frente a esse fato, uma das Coordenadoras da incubadora, no primeiro semestre de 2006, sugeriu e se prontificou a conseguir espaço na própria universidade, tendo em vista ser a atividade produtiva do grupo a reciclagem, o que possibilitou sua articulação com o Laboratório de Resíduos denominado 3 Rs, cujo objetivo é a pesquisa em reciclagem de resíduos. Diante da viabilização do espaço físico para a produção do grupo assinalam-se a sensibilidade, o reconhecimento e envolvimento da comunidade universitária ante a inclusão dessas pessoas em uma atividade econômica, demonstrando que, embora se tenha enfrentado, nesse processo, o preconceito à loucura, encontrou-se solidariedade.

Também se torna importante refletir sobre fato de a 
atividade produtiva ter sido definida anteriormente à sua apresentação para a população alvo, uma vez que essa questão, vez por outra, vem sendo objeto de questionamentos e reflexões por parte de vários atores envolvidos nessa experiência e, até mesmo, por integrantes da equipe. Salienta-se que, como já observado, a atividade foi analisada com os usuários após vários aspectos de sua viabilidade terem sido assegurados e os interessados aderiram de forma livre e esclarecida seguindo os princípios da Economia Solidária.

Ressalta-se ainda que o referencial do método de incubação, orientador das ações dos atores desse processo, aponta que as classes de comportamentos não precisam necessariamente se encontrar presentes em todos os processos e adotar uma mesma sequência. O método também aponta ser relevante a sua adaptação às condições específicas de incubação de cada grupo sem, entretanto, perder-se de vista aspectos essenciais do processo ${ }^{7}$.

Finalmente, salienta-se que, nesse processo, os atores enfrentaram o imaginário social da periculosidade da loucura, o que reforçou a importância do papel dos técnicos em emprestar poder de contratualidade aos usuários. Isso significa utilizar o prestígio social, a delegação social, o saber reconhecido pela sociedade aos profissionais, para proporcionar retorno do sujeito com respeito, ou seja, garantir seus direitos como cidadãos $^{13}$.

A assessoria ao grupo na consolidação do empreendimento

Primeiramente serão apresentadas algumas considerações e reflexões sobre o trabalho da equipe de incubação e sua forma de organização para, em seguida, abordar os demais aspectos da assessoria ao grupo.

Pontuando o trabalho da equipe - apoiando os usuários/trabalhadores na produção, comercialização e inserção em rede

O início da produção do grupo se deu em agosto de 2006, mas a sua consolidação como empreendimento vem se dando ao longo do processo, uma vez que, tanto a produção de papel reciclado e produtos, quanto à sua comercialização, seguindo os princípios da Economia Solidária, eram novos para os atores envolvidos (equipe de incubação e usuários/trabalhadores), sendo fundamental a assessoria da equipe da incubadora.

Durante todo o processo a equipe de incubação vem oferecendo apoio ao grupo em todas as etapas da produção e comercialização do grupo, sempre com a assessoria da equipe da incubadora. Muito embora se verifique que as estratégias de assessoria apontadas nos métodos de incubação consultados ocorrem através de visitas aos grupos, realizadas ora quinzenalmente, ora mensalmente, o apoio da equipe de incubação ao grupo estudado é realizado diariamente. A equipe se reveza para estar presente tanto no processo de produção (diariamente de segunda à sexta-feira, no horário da produção que compreende das 14 às 16 horas, conforme decisão dos trabalhadores), quanto nas assembleias (mensais). Também se faz presente na comercialização realizada em feiras e na inserção em rede o que acontece nos finais de semana e/ou à noite. A equipe apoia o grupo em sua organização e funcionamento, de forma a produzir com qualidade seguindo os princípios da Economia Solidária.

Como estratégia para organização de seu trabalho, a equipe se reúne semanalmente no CAPS, sendo todas as reuniões documentadas em Livro Ata (A). Muito embora se busque um horário comum para participação de todos os seus membros, nem sempre isso é possível, já que todos possuem outras atividades paralelas, o que dificulta a comunicação e compromete sobremaneira o trabalho.

Nota-se a partir do exposto que a consolidação do grupo demanda a presença constante da equipe. Embora a equipe tenha-se pautado na construção de sua prática nos referenciais da desinstitucionalização que "tem como um de seus eixos fundamentais a transformação da relação de tutela, presente nas instituições delegadas da assistência às pessoas com desabilidade e/ou em desvantagem social"14:121 pergunta-se o quanto o seu apoio não representa tutela.

Por outro lado, identifica-se a concepção dialética de tutela como direito à saúde, entendida como emancipação no sentido de que a pessoa, quanto mais 
necessita de proteção, mais deve ser colocada em condição de viver positivamente a própria "minoridade" para reconquistar autonomia e responsabilidade ${ }^{15}$. Sendo assim e, compreendendo tutela neste sentido, entende-se que o intenso estar junto com os "usuários trabalhadores", em todos os momentos constitui-se, no processo de inclusão social pelo trabalho, como tutela de direito à saúde.

O processo de formação dos atores - a capacitação em economia solidária para a atividade produtiva, a gestão administrativa do empreendimento e inserção em rede

Pode-se afirmar, com base na vivência junto ao grupo e na análise dos documentos ( $A, B, C, D, E)$, que, como previsto no método de incubação, a formação dos atores tanto em relação aos princípios da Economia Solidária quanto à atividade produtiva tem se dado num continuum ao longo do processo, em vários momentos e através de várias estratégias.

Dentre os espaços de formação em Economia Solidária para a equipe, ressaltam-se a ACIEPE e as reuniões da incubadora das quais participa, prioritariamente, a Coordenadora Executiva de Projeto de Incubação. Quanto aos alunos, busca-se que todos cursem essa disciplina. Também, com a paulatina integração da equipe nos espaços da Economia Solidária, integrantes da equipe têm sido estimulados a participar de eventos sobre a temática e seus espaços.

Quanto à capacitação dos usuários/trabalhadores em Economia Solidária, verifica-se também a utilização de várias estratégias e espaços como consta no método de incubação. Os primeiros usuários/trabalhadores inseridos no grupo em 2006, juntamente com trabalhadores do CAPS (integrantes da equipe), realizaram uma visita previamente agendada à incubadora, sendo acolhidos por uma de suas Coordenadoras que, cuidadosamente, explicou o que era uma incubadora, sua finalidade e como se dava a assessoria aos empreendimentos. Desse período, encontra-se nos registros $(B, C)$ a participação da Coordenadora docente e de duas integrantes do grupo em uma Feira de Economia Solidária realizada em Campinas em novembro de 2006.

Em face da inserção de novos sócios e da necessidade de treinamento, utilizou-se ainda como estratégia a capacitação concretizada, em 2008, por uma aluna bolsista do curso de Terapia Ocupacional por meio de Projeto de Bolsa Treinamento. Essa formação foi realizada sob orientação da Coordenadora docente demonstrando, mais uma vez, a importante contribuição dos alunos de vários cursos e a concretização da missão da universidade de integrar ensino, pesquisa e extensão.

Além disso, tendo em vista a estratégia de capacitálos conforme o contexto e em um continuum, os sócios vêm, por meio da atuação e articulação da equipe, participando de eventos de Economia Solidária. Pode-se afirmar, ainda, através da experiência de integrar o apoio ao grupo, que a equipe busca, sempre que possível e necessário, retomar os princípios dessa economia no processo de produção e nas assembleias, por serem importantes estratégias para lidar com os conflitos nas relações de trabalho.

A capacitação da equipe e dos sócios para a atividade produtiva, produção de produtos, comercialização e inserção em rede também vêm ocorrendo ao longo do processo. Como estratégia empregada no inicio, verifica-se a capacitação para a produção de papel reciclado e confecção de produtos por meio de visitas técnicas de alguns integrantes da equipe e do grupo a outros serviços, participação em cursos e oficinas oferecidos por recursos da comunidade, assessorias técnicas concretizadas por meio de várias fontes de financiamentos da universidade e do CAPS.

Com base em algumas capacitações, após a inscrição do grupo no CIST e submissão de projeto, o grupo foi contemplado no final de 2008 com a verba do Ministério da Saúde destinada a empreendimentos dessa natureza de acordo com a Portaria GM №. 1169/2005. Essa verba, juntamente com complementação dada pela Secretaria Municipal de Saúde do município, possibilitou a aquisição de dois equipamentos de importância fundamental para o avanço da produção de novos produtos $^{16}$. Atualmente, o grupo conta com recursos financeiros para a compra de novos equipamentos, capacitações e assessorias oriundos de vários órgãos de fomento, como: Fundação de Amparo à Pesquisa do Estado de São Paulo (FAPESP), Financiadora de 
Estudos e Projetos (FINEP) e MEC (Ministério da Educação e Cultura), uma vez que o grupo integra os projetos da incubadora que foi contemplada, além dos recursos oriundos do PRONINC.

Ainda foi necessário e possível estabelecer novas parcerias, o que reforça a importância dessa estratégia nesse processo. Dentre elas ressalta-se a concretizada com a gráfica da universidade, que disponibilizou um profissional para capacitação dos envolvidos no manuseio e manutenção dos novos equipamentos e assessoria na produção de novos produtos ${ }^{17}$. Assim, pode-se constatar um grande avanço do grupo em relação à produção, diversificação e qualidade dos produtos. Também a parceria com a Secretaria do Trabalho, Emprego e Renda da Prefeitura do município por meio do Centro Público de Economia Solidária tem sido importante, uma vez que vem favorecendo a inserção e articulação do empreendimento com os atores do município no campo da Economia Solidária ampliando ainda as possibilidades de comercialização.

Quanto à capacitação dos atores para a gestão administrativa e autogestão, em razão de se tratar de princípios apresentados pela incubadora na sensibilização dos atores da saúde mental, verifica-se, através da análise do Livro de Ata das Assembleias ( $A$ ) do grupo, que essas reuniões são espaços de tomada de decisões desde o início do processo.

Desde as primeiras decisões tomadas, constata-se a divisão das sobras por hora trabalhada e, nesse sentido, um dos primeiros instrumentos da organização do funcionamento do grupo, criado de forma participativa com o próprio grupo foi a Folha de Ponto. Observa-se como outro importante instrumento administrativo do empreendimento a Planilha de Cálculo de Horas Trabalhadas que favorece e capacita os sócios para a contagem das horas. Além disso, um dos alunos bolsistas de extensão elaborou, em 2007, a Planilha de Comercialização com a finalidade de possibilitar a organização, participação e capacitação dos sócios para a comercialização em feiras.

Tendo em vista que muitas das atividades administrativas necessitavam do uso do computador foi se tornando claro para a equipe a necessidade de capacitação dos empreendedores para o domínio dessa ferramenta. Nesse sentido, a Coordenadora Docente direcionou os projetos dos alunos da ACIEPE para desenvolverem treinamento nessa área, o que despertou o interesse de alguns sócios por essa importante ferramenta de trabalho. Também foi oferecido um Curso de Extensão de Inclusão Digital, dirigido aos membros do empreendimento no final de 2008 e início de $2009^{18}$.

Foi possível ainda a integração com o Serviço Nacional de Aprendizagem Comercial (SENAC) por meio do curso de capacitação em "Gestão de Projetos Sociais" em 2009, do qual cinco integrantes do grupo e um membro da equipe de incubação, aluna bolsista de extensão, participaram ${ }^{17}$.

Outra importante ferramenta administrativa proposta pela Coordenadora Docente, no início de 2007, foram as Comissões. Elas foram criadas com o objetivo de auxiliar a organização do processo de trabalho do grupo viabilizando o maior envolvimento e participação dos "usuários trabalhadores" em todas as atividades de planejamento e de administração do empreendimento. Tais Comissões foram criadas de acordo com as necessidades do grupo, compostas por técnicos de incubação e por integrantes do grupo que participam conforme o interesse. Havia demandas nas áreas: Financeira, de Artes, Vendas, Precificação, Compras e Manutenção de Equipamentos.

A partir da vivência de integrar o processo pode-se afirmar que a participação dos sócios nas comissões e assembleias vem crescendo. Esse crescimento é reconhecido também pela equipe, muito embora, às vezes, surjam queixas por parte de alguns de seus integrantes quanto ao não envolvimento dos sócios do grupo. Ainda os técnicos de incubação vêm discutindo a necessidade de melhorar a organização das comissões de forma a criar condições para a efetiva participação dos sócios. Nas assembleias, constata-se que a participação deles vem sendo cada vez mais efetiva, mesmo sendo necessária, ainda, a presença dos técnicos.

Outro avanço do grupo, na área administrativa, referese à obtenção da Carteira do Artesão por dois integrantes, sempre necessária para a concretização de vendas de produtos com nota fiscal para empresas ou 
órgãos, uma vez que o empreendimento não é formalizado. Após longo período de discussão e incentivo da equipe, a obtenção dessa carteira foi concretizada no final do primeiro semestre de $2010 \mathrm{com}$ o apoio de uma técnica de incubação. Esse fato reforça a importância do apoio e presença dos técnicos de incubação nesse processo.

A partir dos aspectos abordados verifica-se que a equipe de incubação tem buscado promover capacitação e responsabilização dos usuários/trabalhadores no planejamento e desenvolvimento de todas as etapas da produção e comercialização. Nesse sentido, vem ao longo do processo trabalhando para que eles assumam as responsabilidades, apoiando-os sempre que necessário a fim de que conquistem a maior autonomia possível e se apropriem cada vez mais do empreendimento. Entretanto, reconhece-se que há necessidade de transformá-los de usuários-trabalhadores em trabalhadores/sócios.

Frente aos comportamentos do método de incubação, observa-se que, muito embora se constate a existência de regras estabelecidas no empreendimento, não foram encontrados documentos referentes às suas normas de funcionamento, em especial, o regimento interno. Como aponta o método de incubação, ele deve ser elaborado o mais precocemente possível e de forma participativa sendo importante para indicar, claramente, comportamentos significativos esperados dos membros e do empreendimento de forma a minimizar conflitos e distorções $^{7}$. Ainda por meio da análise dos comportamentos de incubação do grupo estudado, observou-se que essas normas podem trazer melhorias para o empreendimento, facilitando a organização do processo e aumentando a probabilidade de seus objetivos serem alcançados ${ }^{19}$.

Diante da experiência apresentada percebe-se a complexidade do trabalho de incubar um empreendimento solidário formado por usuários/trabalhadores de um CAPS e a necessidade de ampliação de espaços de capacitação e troca de experiência.

\section{CONSIDERAÇÕES FINAIS}

Ao descrever e refletir sobre essa experiência constata-se o quanto ela tem sido nova para todos os atores envolvidos, havendo ainda escassez de estudos nessa área, o que reforça a contribuição desta pesquisa na produção do conhecimento sobre método de incubação em saúde mental.

$\mathrm{Na}$ apresentação desse processo percebe-se que, muito embora se enfrente preconceito, também se encontra envolvimento e solidariedade por parte da comunidade, o que vem possibilitando vários avanços e conquistas do grupo. Identifica-se também a importância da presença da equipe de incubação entendida como tutela no sentido de direito à saúde e do seu papel de emprestar poder de contratualidade aos empreendedores. Porém ainda se enfrentam desafios: concretizar a autogestão, transformar os usuários em trabalhadores/sócios de um empreendimento solidário e como operacionalizar essa transformação. Frente às demandas de apoio ao grupo, à necessidade da presença constante da equipe e à rotatividade de alguns de seus membros, sugere-se a contratação de um técnico de incubação específico para esse fim.

Finalmente salienta-se a relevância da construção de parcerias e do envolvimento da comunidade. Dentre as parcerias, enfatiza-se a do CAPS com a universidade uma vez que, além de viabilizar a criação do grupo, tem garantido sua sustentabilidade econômica, crescimento e desenvolvimento seguindo os princípios da Economia Solidária. Esse fato reforça a diretriz do Ministério da Saúde sobre a importância da intersetorialidade no processo de inclusão social pelo trabalho de usuários de saúde mental.

\section{REFERÊNCIAS}

1. Brasil. Secretaria de Atenção à Saúde. Reforma psiquiátrica e política de saúde mental no Brasil. Brasília (DF): Ministério da Saúde; 2005. 56p. Documento apresentado à Conferência Regional de Reforma dos Serviços de Saúde Mental: 15 anos depois de Caracas.

2. Brasil. Secretaria de Atenção à Saúde. Grupo de Trabalho, Saúde Mental e Economia Solidária, Instituído pela Portaria Interministerial $n^{\circ} 353$, de 7 de março de 2005. 2006a. Relatório Final... Brasília (DF): Ministério da Saúde [periódico online]. 2006 [capturado em 2009 Mar 13]. Disponível em: http://portal.saude.gov.br/portal/ arquivos/pdf/REL_GT1.pdf 
3. Brasil. Secretaria Nacional de Economia Solidária (SENAES). Atlas da Economia Solidária no Brasil 2005. 2006b. Brasília(DF): Ministério do Trabalho e Emprego; 2006.

4. Brasil. Secretaria Nacional de Economia Solidária (SENAES). Atlas da Economia Solidária no Brasil 2007 Versão Web. 2010. Brasília (DF): Ministério do Trabalho e Emprego [periódico online]. 2010 [capturado em 2010 Mar 30]. Disponível em: http://www.mte.gov.br/sistemas/ atlases/

5. Andrade EP, Duarte MD. Incubadora de cooperativas populares: gerando emprego e renda e fazendo solidária a economia. In: 23․ Encontro Nacional de Engenharia de Produção, 2003, Out 21-24; Ouro Preto [periódico online]. 2003 [capturado em 2010 Mai 24] Disponível em: http://www.abepro.org.br/biblioteca/ENEGEP2003_TR011 3_1144.pdf

6. Dagnino R, Fonseca R. Economia Solidária, incubadoras universitárias, cooperativas e tecnologia: uma definição de papéis. Revista Trimestral de Debate da FASE Pará. [periódico online]. 2007 [capturado em 2010 Mai 24]; [p.16-24] Disponível em: http://www. acompanhamentoproninc.org.br/proposta/proposta 112/re nato.pdf

7. Cortegoso $\mathrm{AL}$, Ioshiaqui $\mathrm{S}$, Zanin M, Amorim DF, Fontes $\mathrm{N}$, Jesus VMB, Cherfem CO, Mascio CC, Conta AAV, Nardini T, Lucas MG. Comportamentos ao incubar empreendimentos solidários: a descrição do fazer coletivo como referencial para o fazer de cada um. In: Cortegoso $\mathrm{AL}$, Lucas MG, organizadores. Psicologia e economia solidária - interfaces e perspectivas. São Paulo: Casa do Psisólogo; 2008. p. 117-36.

8. INCOOP. Incubadora Regional de Cooperativas Populares. São Carlos [periódico online]. 2010 [capturado em 2010 Abr 13]. Disponível em: http://www.incoop. ufscar.br/

9. Lang ABSG. Documentos e depoimentos. In: Lang ABSG, organizador. Reflexões sobre a pesquisa sociológica. São Paulo: CERU; 1992 (Série 2, n.3). p. 78-96.

10. Filizola CLA, Petrilli FJF, Trindade JÁ, David, HG, Brandão $\mathrm{GH}$, Andrade TSC, Barbério, IC. A inclusão social pelo trabalho de usuários do CAPS de São Carlos na perspectiva da Economia Solidária - o processo de implantação. In: Anais do $2^{\circ}$ Encontro Internacional do Grupo Tordesilhas de Enfermagem, 2007 maio 6-9; São Carlos, Brasil. São Carlos (SP): UFSCar; 2007. p.2.

11. Milioni DB. Saúde Mental e inclusão social pelo trabalho na perspectiva da Economia Solidária: a experiência dos integrantes do Recriart [dissertação]. São Carlos: Universidade Federal de São Carlos. Programa de PósGraduação em Enfermagem; 2009.
12. Filizola CLA. Promovendo a inclusão social pelo trabalho de usuários do CAPS de São Carlos na perspectiva da Economia Solidária. Universidade Federal de São Carlos. São Carlos; 2006. Relatório de Atividade de Extensão.

13. Kinoshita RT. Contratualidade de reabilitação psicossocial. In: Pitta A. Reabilitação psicossocial no Brasil. São Paulo: Hucitec; 1996. p.55-9.

14. Nicácio F, Kinker FS. O desafio do viver fora: construindo a cooperativa Paratodos. In: Campos FCBC, Henrique CMP, organizadores. Contra a maré à beira mar: a experiência do SUS em Santos. São Paulo: Página Aberta; 1996. p. 121-31.

15. Basaglia FO. Mário Tommasini: vidas e feitos de um democrata radical. São Paulo: Hucitec; 1993.

16. Filizola CLA. Promovendo a inclusão social pelo trabalho de usuários do CAPS de São Carlos na perspectiva da Economia Solidária. 2009a. São Carlos: Universidade Federal de São Carlos; 2009. Relatório de Atividade de Extensão.

17. Tagliaferro $P$ et al. Atores envolvidos no processo de incubação de empreendimento solidário de reciclagem de papel em saúde mental e importância da construção de parcerias. In: Zanin M, Gutierrez RF, organizadores. Economia solidária: tecnologias em reciclagem de resíduos para geração de trabalho e renda. São Carlos: Claraluz, 2009. E-book. p 205-207 [publicação online]. 2009 [capturado em 2010 Mai 24]. Disponível em: http://www.conaresol.ufscar.br/download/EbookFINAL.pdf

18. Filizola CLA. Promovendo a inclusão social pelo trabalho de usuários do CAPS de São Carlos na perspectiva da Economia Solidária. 2009b. São Carlos: Universidade Federal de São Carlos; 2009. Proposta de Atividade de Extensão.

19. Andrade TSC. Economia Solidária e Saúde Mental: comportamentos de mediadores de processos de incubação de empreendimentos solidários para a inclusão social e econômica de pessoas com transtornos mentais. São Carlos: Universidade Federal de São Carlos; 2008. 80p. Trabalho de Conclusão de Curso.

\section{Endereço para correspondência}

Priscila Tagliaferro Rojo

Rodovia Washington Luís km 235

São Carlos/SP - CEP 13565-905

Telefone: +55 1187221710

Email: pri_taglia@yahoo.com.br 